\title{
The factors affecting vitreous hemorrhage after vitrectomy in diabetics
}

\author{
Yakup Aksoy, MD \\ Department of Ophthalmology, Hakkari Military Hospital, Hakkari, Turkey
}

Dear Editor,

We have read with great enthusiasm the recently published article entitled "Use of intravitreal bevacizumab or triamcinolone acetonide as a preoperative adjunct to vitrectomy for vitreous haemorrhage in diabetics" by Ferraz et al. ${ }^{1}$. We congratulate the authors for their lightening study. In that well-designed study, Ferraz and coworkers tried to evaluate the effect of preoperative intravitreal bevacizumab (IVB) or triamcinolone (IVT) on the rate of early postvitrectomy hemorrhage in proliferative diabetic retinopathy (PDR). They concluded that intravitreal injection of bevacizumab 1 week before vitrectomy seems to reduce the incidence of early postvitrectomy hemorrhage in diabetic patients. We think that the factors which can affect the vitreous hemorhage (VH) after vitrectomy in diabetics are not completely discussed in this study and we would like to make some contributions about this.

Diabetic retinopathy is one of the most important causes of low vision and low quality of life in diabetic patients ${ }^{2-4}$. VH is a serious complication of vitrectomy for proliferative diabetic retinopathy $y^{5}$. There are many factors that affect $\mathrm{VH}$ after vitrectomy in diabetics. Khuthaila et al. reported in their study that the rate of VH was lower in patients with complete scatter photocoagulation before undergoing PPV compared with patients with incomplete scatter photocoagulation $(\mathrm{p}=.002)$. And also other factors that cause higher postoperative $\mathrm{VH}$ rate is reported as younger age $(\mathrm{p}=.022)$ and phakia $(\mathrm{p}=.036)^{6}$. Lee et al. informed that patients who experienced postoperative hypotony had an 11.20-fold increased risk of immediate postoperative $\mathrm{VH}^{7}$. The authors didn't mention about if there was any difference in these factors betwen groups in present study. We believe that these factors should be taken in to consideration when creating study groups and analysing the results in the future studies. Because the presence any of these factors probably would cause the rate of postvitrectomy VH to be higher than it should be.

\section{RefERENCES}

1. Ferraz DA, Morita C, Preti RC, Nascimento VP, Maia Junior OO, Barros AC, et al. [Use of intravitreal bevacizumab or triamcinolone acetonide as a preoperative adjunct to vitrectomy for vitreous haemorrhage in diabetics]. Rev Bras Oftalmol. 2013;72(1):12-6. Portuguese.

2. Bittencour ZZ, Montilha RC, Gasparetto ME, Temporini ER, Carvalho KM. [Diabetic retinopathy and visual disabilities among patients in a rehabilitation program]. Rev Bras Oftalmol. 2011;70(6):342-8. Portuguese.

3. Mendonça RH, Zihlmann KF, Freire ML, Oliveira RC, José NK. [Quality of life in patients with proliferative diabetic retinopathy]. Rev Bras Oftalmol. 2008; 67(4):177-83. Portuguese.

4. Motta MM, Coblentz J, Melo LG. [Recent aspects on physiopathology of diabetic macular edema]. Rev Bras Oftalmol. 2008;67(1):45-9. Portuguese.

5. Fabinyi DC, O’Neill EC, Connell PP, Clark JB. Vitreous cavity haemorrhage post-vitrectomy for diabetic eye disease: the effect of perioperative anticoagulation and antiplatelet agents. Clin Experiment Ophthalmol. 2011;39(9):878-84.

6. Khuthaila MK, Hsu J, Chiang A, DeCroos FC, Milder EA, Setlur V, et al. Postoperative vitreous hemorrhage after diabetic 23-gauge pars plana vitrectomy. Am J Ophthalmol. 2013;155(4):757-63, 763.e1-2.

7. Lee BJ, Yu HG. Vitreous hemorrhage after the 25-gauge transconjunctival sutureless vitrectomy for proliferative diabetic retinopathy. Retina. 2010;30(10):1671-7. 